\title{
CAN WE WALK? VISIBILITY OF THE PEDESTRIAN WAYS
}

\author{
Shanty Silitonga \\ Faculty of Engineering Catholic University of Saint Thomas, Medan, Indonesia \\ Jl. Setia Budi, Kp. Tengah, Kec. Medan Tuntungan, Kota Medan \\ *Email: shanty.silitonga@gmail.com
}

\begin{abstract}
Walking is the simplest way of transportation, it is universal, healthy and fun. The purpose of the pedestrian pathways is to reduce the level of dependency of the community against the motor vehicles traffic and creating environmental aspect by introducing a system of human scale. Designing a good promenade should be able to meet the four factors; safety, convenience, comfort and attractiveness. Pedestrian pathways as a public space should be freely accessible physically for everyone, therefore it must have visibility so that it can function optimally as a public space. This research conducted a study about the visibility of pedestrian pathways in Saint Thomas Catholic University in Medan Indonesia. This research uses descriptive qualitative research method. The study found that the pedestrian pathways in the campus do not have good visibility, pedestrian pathways was somehow shown disjointed and uncomfortable.
\end{abstract}

Keywords: walking, visibility.

\section{INTRODUCTION}

Walking is the simplest form of transportation, it is universal, cheap, connects various transportation modes and also healthy and enjoyable (Litman, 2011). Walking is a favorite choice to circulate in and out of campus, in fact, on many campuses it is the main way of circulation. As the main circulation, walking must be pleasant and comfortable, that is why we need a good pedestrian pathways. Designing a good promenade should be able to meet the four (4) factors, they are safety, convenience, comfort and attractiveness (Utterman, 1984). Pedestrian pathway as a public space should be accessible physically for everyone. The Pedestrian pathways must have visual clarity or commonly known with visibility so that it can function optimally as a public space.

Walking is the most widely performed on the campus of St. Thomas Catholic University (or UNIKA St.Thomas), but unfortunately the existing pedestrian pathways are disjointed and uncomfortable to walk. This study will examine the visibility of pedestrian pathways in UNIKA based on the elements of visibility by Thibaud.

\section{LITERATURE REVIEW}

A good space is a used space and people's behavior, movement and use are directly related to the visual created by the spatial configuration i.e. visibility. Visibility and visual perception are of a great importance on how we behave, appreciate and experience the environment and could be determinant factors in designing urban spaces. The understanding of visibility and people's perception is not only a critical key to analytical purpose but also a tool to producing more livable spaces (Bada and Guney, 2009).

The concept of visibility or visual perception has long appeared. In the 1970s appeared two approaches in analyzing the visibility; the first is the concept of viewshed in terrain and landscape analysis and the concept of isovist in architecture and urban space. Numbers of researchers showed their interests in the research of isovist and found a few new ways for the acquisition of spatial indexes from the isovist idea, which could be applied to describe the figures like space volume, openness, and also visibility (Turner, et. al, 2001). 


\section{Visibility of Pedestrian pathway}

The pedestrian pathway is defined as the movement of people from one place to destination place on foot (Utterman, 1984). The pedestrian pathway is also an interesting area for social events, soul, and spiritual development, for example, for nostalgia, sudden meeting, leisure, and so on. Pedestrian pathway at the present moment can be a sidewalk, pavement, sidewalk, the plaza and the mall. Pedestrian pathway has an important role in selling and facilitating a culture of a city. Therefore, an understanding of the space in a city should not just limit to the physical form but also understand the functions on a daily basis, how local people use it as well as the history of these spaces (Hanan, 2012).

Pedestrian pathways in urban areas can serve as elements that influence the development of urban life, i.e. it can be a healthy activity, reduce the level of criminality, open a chance to the potential business that can improve the economy, the media promotions, presenting an atmosphere and environment that is dynamic and can be an identity in urban areas, reducing air pollution and noise pollution due to a decrease in the number of motor vehicles. But the fact is, half of the number of motor vehicle accidents involving pedestrians (Boyce \& Geller, 2000). According to Azrin (1977) to improve the security of pedestrian, a strategy needs to be prepared, for example by providing certain information at the point of cartilage. In addition, one thing about the pedestrian pathway is how to design the pedestrian pathway in order to create comfortable and attractive pathways. Comfort according to Weisman (1991) is the state of the environment which gives sense to the five senses and anthropometry accompanied facilities that comply with its activities. It is also stated by Utterman (1984) where he mentions the criteria to be met in the design of a good promenade is security, where pedestrian pathways must be safe from the threat of accidents, even criminality. Furthermore, the ease. A good pedestrian pathway is the shortest path which is easily accessible and free from obstacles. Any comfort factors must be met, where pedestrian must be able to feel comfortable in a pedestrian pathway and the last is the presence of a factor of attractiveness, both originating from the promenade, supporting elements, light elements or illumination. Comfort on the pedestrian pathway was also influenced by the material, for example the surface material. Surface material, dimensions, color and texture of the surface turns to the convenience for pedestrian (Prijadi, et. all, 2001).

A place is a public space if it is accessible to everyone where everyone is physically located and can be freely move (Thibaud, 2001). The ease of access can also help someone to orient in a neighborhood, if the relationship between a person and physical environment creates no harmony then it will produce disorientation. One of the solutions to avoid disorientation is to create an environment that has its own character or ' unique ' which not only provides security but also deepen and enhance the intensity of someone's experience (Lynch, 1960 in Kalin, Yilmaz, 2012). Relationships and the intensity of the experience in a neighborhood can be affected by the visibility of the environment. A pedestrian pathway must have clarity or visibility so that it can function optimally as a public space.

Although there are many different ways to analyze the visibility, there are some simple ways that can be applied mainly on the scale of a smaller environment. In some traditional practices, the views of pedestrian walking in the urban open space were recorded through photographs or sketches in order to understand the visual effects (Yang et al 2007). One simple way to find out the visibility is by analyzing the dark or bright side of the pedestrian pathway. The human body perceives a place through the five sensories; vision, hearing, smell, taste and touch. A methodology that measures the visibility of an environment from the human vision was conceived by Thibaud who stating that there are 5 elements visibility in an environment, that is, overexposure, enclosure, filtering, blurring and silhouetting.

\section{METHODOLOGY}

This research will analyze fifth element concerning visibility based on human vision stated by Thibaud i.e. overexposure, enclosure, filtering, blurring and silhouetting. Research method that will be used is qualitative methods using observation or direct observation and depth interview. This is chosen because the observation area is very important and useful because it gives a direct experience of the researcher with his research area (Cresswell, 1994). By observing the area researcher can find 
out and identify the conditions of the research area. Observations provide data and information that is much more fully and clearly than with depth interview and questionnaire (Marshall, 1995; Sinulingga, 2012).

Periodic observation and photography (visual) are used as a technique for documenting how the existence of a fifth element visibility of Thibaud on the pedestrian pathways in the study area. The parameters that will be recorded in the field are as follows.

Table 3.1. Research parameters

\begin{tabular}{|c|c|c|}
\hline $\begin{array}{l}5 \text { elements of } \\
\text { visibility of } \\
\text { Thibaud } \\
\end{array}$ & Information & Parameters \\
\hline Overexposure & $\begin{array}{l}\text { Overexposure creates difference or hierarchy } \\
\text { among the objects visually and can increase } \\
\text { the visibility of an object, can be done in two } \\
\text { ways: } \\
\text { - obfuscate or clarify something in a space } \\
\text { - displays a view from the top }\end{array}$ & $\begin{array}{l}\text { a. The pedestrian pathways clearly } \\
\text { visible or unclear or fuzzy } \\
\text { b. The pedestrian pathways are clearly } \\
\text { visible from the } 2 \text { nd floor }\end{array}$ \\
\hline Enclosure & $\begin{array}{l}\text { The function of the enclosure is to plan or } \\
\text { structure and direct, can create a focus on one } \\
\text { particular thing by way of disguising more or } \\
\text { even can unify all things into one unity. }\end{array}$ & $\begin{array}{l}\text { a. pedestrian pathways can direct } \\
\text { pedestrian } \\
\text { b. Pedestrian pathways can unite the } \\
\text { various functions or areas }\end{array}$ \\
\hline Filtering & $\begin{array}{l}\text { Filtering can result in an ambiguous } \\
\text { relationship between the outer and the inner } \\
\text { space, creating the various types of lighting in } \\
\text { a place depend on a climate or weather. }\end{array}$ & $\begin{array}{l}\text { The Sun made a pedestrian pathways be } \\
\text { clear or not clear (anti-glare) }\end{array}$ \\
\hline Blurring & $\begin{array}{l}\text { The aim of blurring is to disguise where one } \\
\text { can hardly be aware of the presence of others, } \\
\text { creating a ' mystery ' or ' surprises ' can even } \\
\text { be made to } \\
\text { 'hide'. }\end{array}$ & $\begin{array}{l}\text { Pedestrian pathways may or may not be } \\
\text { viewed on a rainy or at late afternoon }\end{array}$ \\
\hline Silhouetting & $\begin{array}{l}\text { Silhouetting emphasis on the contour of an } \\
\text { object or a person rather than the details, } \\
\text { simple example is ' backlight'. }\end{array}$ & $\begin{array}{l}\text { Physical form of pedestrian pathways } \\
\text { clearly visible is the transition from one } \\
\text { place to another (clear difference } \\
\text { between the front and the end part) }\end{array}$ \\
\hline
\end{tabular}

Depth interview will be done to the users of the pedestrian pathways in the campus UNIKA St. Thomas, such as students or lecturers and employees of the university. Respondents were taken using a simple random sampling method surroundings Faculty of Engineering. Depth interview was conducted to strengthen the survey results, this was chosen because the most appropriate method to know the reaction and action of a place and its people is to ask directly to the community and observe their behavior and also because the interview is a direct conversation, flexible, clear and fast. The data resulting from field survey will be analyzed based on parameters of the fifth element visibility according to Thibaud. The results of the analysis will be strengthened again with the results of the depth interviews. From the results of the analysis, it will be generated to answer how the visibility of pedestrian pathways within the research area is.

\section{DISCUSSION AND ANALYSIS}

Elements of overexposure on the pedestrian pathways in the campus UNIKA St. Thomas are good. Thibaud stated that overexposure can be generated in two ways; with obscure or clarify something or displaying the view from the top. There is a difference or hierarchy among the pedestrian pathways in UNIKA St.Thomas, and as a result it can increase the visibility of the pedestrian 
pathways. There is a difference on their material, color, the difference in altitude (Figure 3 ). The presence of separators on both sides of the pedestrian pathways i.e. canstein make a difference. The existence of such differences makes the path line can be seen in the environment. But pedestrian pathways on the campus of UNIKA are not clearly visible if seen from the second floor. This is due to the pedestrian pathway is covered by vegetation.

The difference in height or hierarchy is only found on the pedestrian pathway path at the entrance of the campus while there is none in the other part (Pic.2). That hierarchy of the pedestrian pathways is very important because with the difference or hierarchy the pedestrian pathways can be seen clearly even can attract attention. Of 50 (fifty) respondents, twenty respondents stated that pedestrian pathways clearly visible. Thirty respondents declared doubt about this because of the pedestrian pathway is disjointed. Disjointed pathways strongly interfere the clarity and orientation for the pedestrian. This is unfortunate because the clarity of the promenade is one of the elements that make up the visibility.

Elements of the Enclosure on the campus of UNIKA are not good. The function of the enclosure is to plan or structure and direct, it can create a focus on one particular thing by way of disguising others or in other hand can even unify all things into one unity. The enclosure is an experience that must exist in a city because it can allows someone to understand the conditions of a landscape through relations between human beings and the environment. Pedestrian pathways that have a visibility is a promenade which can direct pedestrians and unite the various functions in a region. The research found that the pedestrian pathways in UNIKA are not able to drive the pedestrian and did not manage to unite the various functions in the campus environment. The pathways are disjointed, only di particular area (Figure 3).

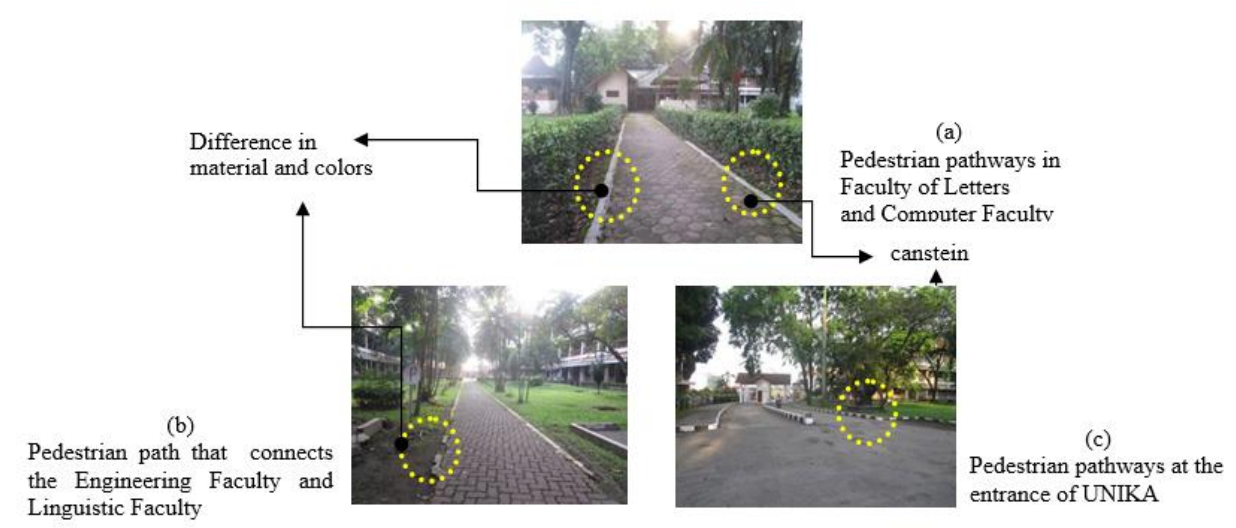

Figure 1. The hierarchy on the pedestrian pathways in area of research
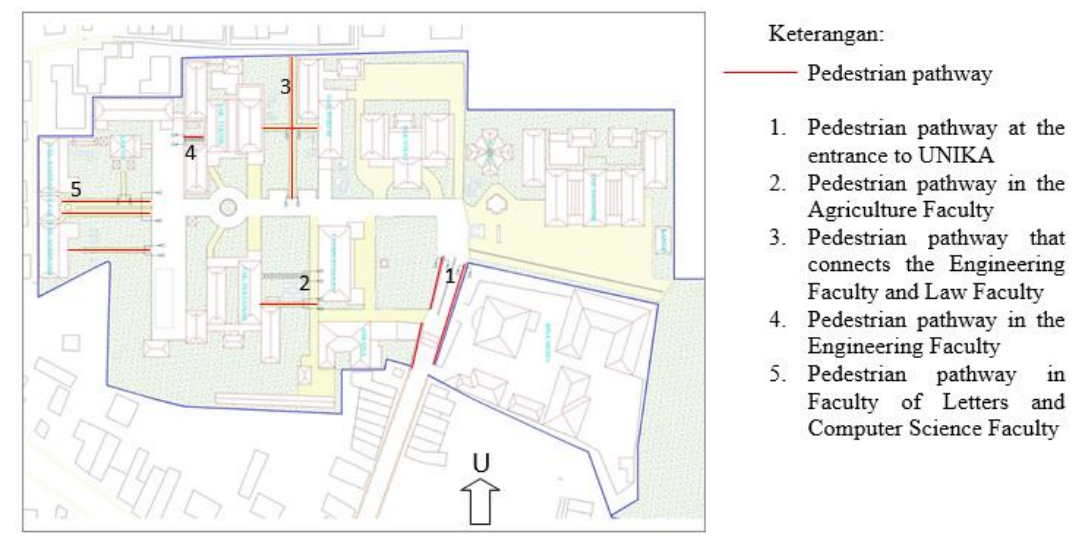

Figure 2. The pedestrian pathways on the UNIKA disjointed and only in some parts of the campus 
Filtering elements on pedestrian pathways the campus of UNIKA St. Thomas are good. Thibaud stated that filtering produces an ambiguous relationship between the outer and the inner space, it also creates various types of lighting in a place with a climate or weather dependent. This research used sunlight as filtering's parameter, how it's create pedestrian pathways become evident or even be unclear or glare. Pedestrian pathways that have a visibility can be seen clearly in the daytime as well as night, it would be better if have a design. It will create a walking experience for pedestrians. The research found that pedestrian pathways in the campus of UNIKA St. Thomas have good filtering element. It is visible in daylight and there it is no covered with vegetation (Figure 3 ).

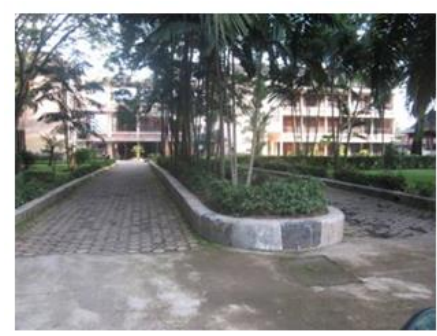

(a)

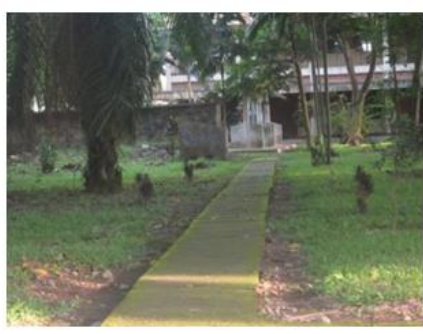

(b)

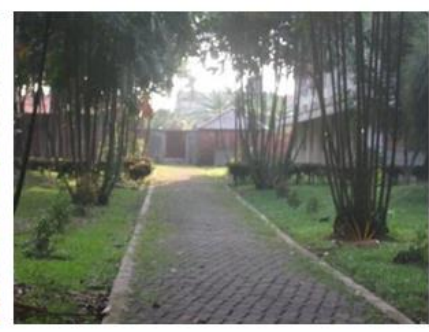

(c)

(a) Pedestrian pathways in Linguistic Faculty and Computer Science Faculty (Pic.2 No.5)

(b) Pedestrian pathways in Linguistic Faculty and Computer Science Faculty (Pic.2 No.5)

(c) Pedestrian pathways that connect Engineering Faculty and Law Faculty (Pic.2 No.3)

Figure 3. Condition of pedestrian pathways in UNIKA St.Thomas

Blurring elements on pedestrian pathways in the campus of UNIKA St. Thomas are not good. The aim of blurring is to disguise where one can hardly be aware of the presence of others, creating a ' mystery ' or ' surprises ' or can even be made to ' hide '. In another interpretation, blurring can be made to produce a condition that accentuates the characteristics of a place or dramatizes things. In this research area, the element of blurring was examined whether the pedestrian pathways can be used when it rains. Fifty respondents stated that they did not feel comfortable walking when its rain, this is due to the lack of protective items in the pedestrian pathways and the condition of surface material (slippery).

Silhouetting elements on pedestrian pathways in the campus of UNIKA St. Thomas are not good. Silhouetting can create accents of transition from one place to another and clearly distinguish the front with the middle part or the end part. In this study, researchers make the clarity of the beginning and end part of a pedestrian pathways as indicators of silhouetting. Fifty respondents stated that they could not see clearly within the pedestrian pathways, there are physical problems and it is disjointed.

\section{CONCLUSIONS AND RECOMMENDATION}

This research concludes that the visibility of pedestrian pathways on the campus of UNIKA St. Thomas is relatively not good.There are three elements that must be fixed, i.e. blurring, enclosure and silhouetting. As a first step, the researcher suggested that the pedestrian pathways on the campus should be made to converge, not disjointed. Pedestrian pathways must be able to unite every functions even on every corner of the campus.

\section{Daftar Pustaka}

Azrin, Nathan H. (1977) A Strategy For Applied Research: Learning Based But Outcome Oriented. American Psychologist. 32(2). 140-149.

Bada, Yassine; Guney, Yasemin. (2009) Visibility and Spatial Use in Urban Plazas A Case Study from Biskra, Algeria. Proceedings of the 7th International Space Syntax Symposium. 
Boyce, Thomas G. dan Geller, E. Scott. (2000) A Community-Wide Intervention to Improve Pedestrian way Safety Guidelines for Institutionalizing LargeScale Behavior Change. 32 (4). 502520.

Creswell, J.W. (1994) Research Design: Qualitative and Quantitative Approach. California: Sage Publication Inc.

Hanan, Himasari (2012) Pedestrian Ways, Informalities and Urban Spectacles. Procedia-Social and Behaviour Sciences 36 (2012) p.421-430.

Leduc T., Tourre V., Woloszyn P., Miguet F. (2011) Measuring Surrounding Space to Assess the Pedestrian way Visual Aperture Angle in the Urban Fabric: Toward a Kurtosis-Based Isovist Indicator. Information Fusion and Geographic Information Systems, Chapter 11, pp. 129-142.

Kalin, Arzu; Yilmaz, Demet (2012) A Study On Visibility Analysis of Urban Landmarks: The Case of Hagia Sophia in Trabzon. METU JFA 2012 (29:1) p.241-271.

Litman, Todd Alexander (2011) Economic Value of Walkability. Vol. 10. Victoria.

Marshal, K.A; Kelly, F.J; McNeil, J.T. (1995) Testing Research Hypotheses Using Multiple Linear Regression. Southern Illinois University Press, Carbondale Illinois.

Prijadi, Rachmat; Sangkertadi; Tarore, Raymond, Ch. (2014) Pengaruh Permukaan Jalur Pedestrian way Terhadap Kepuasan dan Kenyamanan Pejalan Kaki di Pusat Kota Manado. Media Matrasain. Vol 11 no 1. ISSN 18581137.

Sinulingga, Sukaria (2012) Metode Penelitian. USU Press. (2).

Thibaud, Jean-Paul (2001) Frames of Visibility in Public Space. Places 14:1 p:42-47.
Turner A., (2001) From Isovist To Visibility Graphs: a Methodology For The Analysis of Architectural Space. Environment and Planning B,28, 103121.

Utterman, R. K. (1984) Accommodating The Pedestrian way. Van Nostrand Rainhord Company. New York.

Yang P. P., Putra S. Y., Li W. J. (2007) Viewsphere: a GIS-based 3D visibility analysis for urban design evaluation. Environment and Planning B: Planning and Design, volume 34, pp.971-992.

Weisman, J. (1981) Modelling Environment Behavior System. Journal of Man Environment Relation. 